\title{
Hydroxyapatite Foam as a Catalyst for Formaldehyde Combustion at Room Temperature
}

\author{
Jing $\mathrm{Xu}^{\dagger}{ }^{\dagger}$ Tim White, ${ }^{\ddagger}$ Ping $\mathrm{Li}^{\dagger}{ }^{\dagger}$ Chongheng $\mathrm{He},{ }^{\dagger}$ and $\mathrm{Yi}^{-}$-Fan $\mathrm{Han}^{*, \dagger}$ \\ State Key Laboratory of Chemical Engineering, East China University of Science and Technology, \\ Shanghai 200237, People's Republic of China, and Centre for Advanced Microcopy, Australian National \\ University, Canberra ACT 2601, Australia
}

Received July 14, 2010; E-mail: yifanhan@ecust.edu.cn

\begin{abstract}
The excellent performance of hydroxyapatite, a novel non-precious metal catalyst, for formaldehyde ( $\mathrm{HCHO}$ ) combustion at room temperature is reported. Temperature-programmed surface reaction results indicated that hydroxyl groups bonded with the channel $\mathrm{Ca}^{2+}$ may be responsible for adsorption/ activation of $\mathrm{HCHO}$.
\end{abstract}

Formaldehyde (HCHO) is an irritant and carcinogenic volatile organic compound (VOC) released primarily by the degassing of urea-formaldehyde insulation finishing materials; it is also found in particle board and sealants. It is of particular concern in airtight, energy-conserving buildings, as the U.S. Environmental Protection Agency (EPA 600/x-85/362) reports that acute and chronic (longterm, $0.003 \mathrm{ppm})$ inhalation can lead to eye, nose, and throat inflammation and possibly lung and nasopharyngeal cancer. As a significant segment of the public is exposed to formaldehyde at levels high enough to produce symptoms, an effective means to remove its vapors from closed spaces is of importance.

Combustion of HCHO is presently carried out over precious metal catalysts, such as platinum or palladium. ${ }^{1-3}$ It has been found that the concentration of formaldehyde in a two-bedroom house could be reduced from $0.1-0.2$ to $0.02-0.05 \mathrm{ppm}$ on a $1 \mathrm{wt} \% \mathrm{Pd}$ or $\mathrm{Pt} / \mathrm{Al}_{2} \mathrm{O}_{3}$ catalyst at $573 \mathrm{~K},{ }^{3}$ while Imamura et al. ${ }^{4}$ reported complete conversion of $\mathrm{HCHO}(900 \mathrm{ppm}$ in air) at the lower temperature of $473 \mathrm{~K}$ on a $\mathrm{Ru}(5 \mathrm{wt} \%) / \mathrm{CeO}_{2}$ catalyst. However, these are expensive procedures due to the high precious metal loading and elevated operating temperatures. In response, a Pt $(15 \mathrm{wt} \%) / \mathrm{SnO}_{2}$ catalyst was designed that exhibited high reactivity near room temperature, ${ }^{5}$ and most recently, complete combustion was achieved at $360 \mathrm{~K}$ over a $\mathrm{Mn}(18.2$ wt $\%)-\mathrm{Pd}(0.44 \mathrm{wt} \%) / \mathrm{Al}_{2} \mathrm{O}_{3}$ co-catalyst in a mixture of $0.53 \% \mathrm{HCHO}$ and air. ${ }^{3}$ Therefore, alternate low-capital-cost and energy-efficient catalytic systems that promote combustion or oxidation of VOCs at room temperature are desirable.

This paper describes a novel alternative where hydroxyapatite (HAp) catalyzes the low-temperature combustion of VOCs without the need to fabricate a metal composite. Hydroxyapatite adopts the ideal composition $\mathrm{Ca}_{10}\left(\mathrm{PO}_{4}\right)_{6}(\mathrm{OH})_{2}$ and possesses a zeolite-like frame that is thermally stable $(>1000 \mathrm{~K})$ and contains both acid and base sites, including hydroxyl-enriched channels. ${ }^{6}$ The morphology and fine structure of HAp were inspected by scanning electronic microscopy (SEM) and transmission electron microscopy (TEM) (Figure 1). Cation-exchanged and metal-loaded HAp's are versatile catalysts for Diels-Alder and Aldol reactions, ${ }^{7}$ aerobic oxidation of alcohols, ${ }^{8}$ transformation of ethanol into value-added chemicals, ${ }^{9}$ decomposition of hydrogen peroxide, ${ }^{10}$ and wet peroxidation of VOCs. ${ }^{11}$ Here, we report for the first time the remarkable activity of the phase-pure HAp

\footnotetext{
East China University of Science and Technology.

* Australian National University.
}

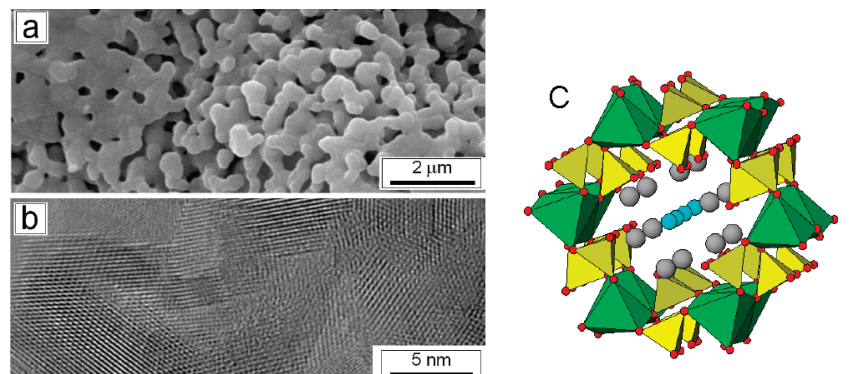

Figure 1. Morphology of HAP: (a) SEM, (b) TEM, and (c) structure drawings of $P 63 / m\left[\mathrm{Ca}_{4}^{\mathrm{I}} \mathrm{Ca}^{\mathrm{II}}{ }_{6}\right]\left(\mathrm{PO}_{4}\right)_{6}(\mathrm{OH})_{2}$ hydroxyapatite. The green polyhedra indicate $\mathrm{Ca}^{\mathrm{I}} \mathrm{O}_{6}$ metaprisms, the yellow polyhedra indicate $\mathrm{PO}_{4}$ tetrahedra, gray spheres correspond to $\mathrm{Ca}^{\mathrm{II}}$, and blue spheres correspond to $\mathrm{OH}$.

form as a novel non-precious metal catalyst for the combustion of formaldehyde under ambient conditions.

To provide a baseline for comparison, a supported precious metal catalyst, $\mathrm{Pd}(3$ wt $\%) / \gamma-\mathrm{Al}_{2} \mathrm{O}_{3}$, was measured simultaneously. Details concerning the methodologies employed can be found in the Supporting Information. It was found that at $298 \mathrm{~K}$ the conversion of $\mathrm{HCHO}\left(X_{\mathrm{HCHO}}\right.$ ) was ca. $45 \%$ for $\mathrm{HAp}$, only slightly lower than for the Pd catalyst (ca. 57\% in Figure 2a). The $X_{\mathrm{HCHO}}$ increased steadily with temperature for both catalysts, with $100 \%$ conversion achieved at $525 \mathrm{~K}$ for HAp and at $475 \mathrm{~K}$ for Pd. On the other hand, when ambient conditions were maintained, $X_{\mathrm{HCHO}}$ over HAp remained stable at $45 \%$ for the first $2 \mathrm{~h}$ of reaction but dropped to $28 \%$ after running for $10 \mathrm{~h}$, while for the Pd catalyst it declined rapidly from $57 \%$ to $33 \%$ (Figure $2 \mathrm{~b}$ ). Additionally, the turnover rate is $0.0086 \mathrm{~s}^{-1}$ for HAp and $0.006 \mathrm{~s}^{-1}$ for the Pd catalyst at $298 \mathrm{~K}$. The methods for calculating the mass-specific and turnover rates are described in Table S1 (Supporting Information).

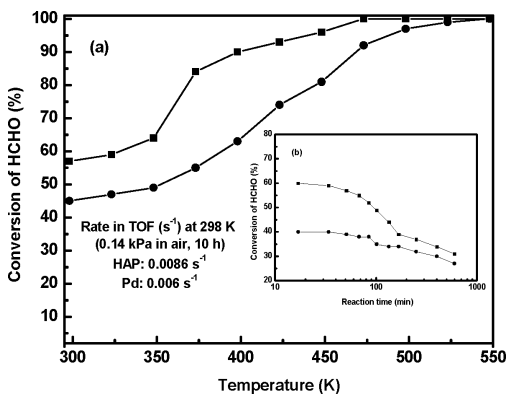

Figure 2. (a) $\mathrm{HCHO}$ combustion in the temperature range $298-550 \mathrm{~K}$. (b) $\mathrm{HCHO}$ combustion at $298 \mathrm{~K}$ for $10 \mathrm{~h}$. Catalysts, (ם) Pd (3 wt \%)/ $\gamma$ $\mathrm{Al}_{2} \mathrm{O}_{3}$ or $(\bullet) \mathrm{HAp}$; feed gas, $0.14 \mathrm{kPa} \mathrm{HCHO}, 2.6 \mathrm{kPa} \mathrm{H} \mathrm{H}_{2} \mathrm{O}$ in air; GHSV, $36000 \mathrm{~h}^{-1}$. HCHO conversion was calculated on the basis of $\mathrm{CO}_{2}$ formation. 

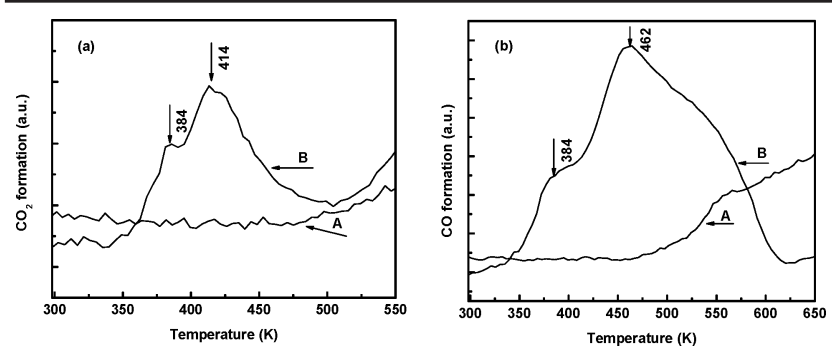

Figure 3. TPSR spectra of (a) $\mathrm{CO}_{2}$ formation and (b) $\mathrm{CO}$ formation obtained from the reaction between $\mathrm{HCHO}$ and pre-adsorbed oxygen over (A) HAp and (B) Pd (3wt \%)/ $\gamma-\mathrm{Al}_{2} \mathrm{O}_{3}$ catalysts.

Clearly, HAp exhibits superior activity and stability toward $\mathrm{HCHO}$ combustion under ambient conditions and, to the best of our knowledge, is the first non-precious metal catalyst to demonstrate excellent performance in this reaction system.

To probe the active sites in HAp and study the adsorbed HCHO and its oxidized products during reaction, temperature-programmed surface reaction (TPSR) spectra arising from the interaction between $\mathrm{HCHO}$ and pre-adsorbed oxygen were recorded for both catalysts. In the $\mathrm{HCHO}$ flow stream, neither $\mathrm{CO}_{2}$ (curve $\mathrm{A}$ in Figure 3a) nor $\mathrm{CO}$ (curve $\mathrm{A}$ in Figure $3 \mathrm{~b}$ ) was generated over an oxygenpreadsorbed HAp until the temperature was $>500 \mathrm{~K}$. In contrast, for the $\mathrm{Pd}$ catalyst, $\mathrm{CO}_{2}$ production occurred at 384 and $414 \mathrm{~K}$ (curve B in Figure 3a), and CO appeared at 384 and $462 \mathrm{~K}$ (curve $\mathrm{B}$ in Figure $3 \mathrm{~b}$ ); similar to $\mathrm{HAp}, \mathrm{CO}_{2} / \mathrm{CO}$ concentrations rose beyond $500 \mathrm{~K}$.

It can be inferred from these results that (i) the adsorbed oxygen is weakly bonded to HAp and unlikely to be involved in formaldehyde oxidation and/or (ii) the adsorption of oxygen takes place only in the presence of $\mathrm{HCHO}$, as $\mathrm{O}_{2}$ temperature-programmed desorption spectra from HAp do not contain significant peaks from 298 to $550 \mathrm{~K}$ (not shown for brevity). While minor $\mathrm{O}_{2}$ adsorption on HAp cannot be entirely excluded, it is noted that the dissociative adsorption of oxygen on bare HAp has not been reported. Therefore, it is logical to suppose that the hydroxyl groups located in the HAp channels take part in activating/oxidizing the $\mathrm{HCHO}$ molecule, in a catalytic cycle that will be established later.

For the Pd catalyst it is clear that $\mathrm{HCHO}$ or its dissociative species react with adsorbed oxygen to produce $\mathrm{CO}_{2}$ and $\mathrm{CO}$ below $500 \mathrm{~K}$. As there are two maxima in the TPSR spectra (Figure 3b), there are at least two distinct active sites on the Pd surface. CO may arise indirectly from partial oxidation of $\mathrm{HCHO}$ when limited oxygen is available on the surface or directly as an intermediate during $\mathrm{HCHO}$ dissociation. For both catalysts, the enhanced production of $\mathrm{CO}$ and $\mathrm{CO}_{2}$ above $500 \mathrm{~K}$ (Figure $3 \mathrm{~b}$ ) can be attributed to the decomposition/disproportionation of $\mathrm{HCHO}$. This conclusion was substantiated by running the same experiment on a reduced $\mathrm{Pd}$ surface that only generated $\mathrm{CO} / \mathrm{CO}_{2}$ at high temperature (Figure S3, Supporting Information). Discussion of the surface reactions at elevated temperatures is beyond this study, but it is likely that the pathways for $\mathrm{HCHO}$ combustion on the two catalysts are remarkably different.

The diverse functionality of HAp as a catalyst and biocompatible material is achieved, in part, through the limited replacement of $\mathrm{Ca}^{2+}$ and $\mathrm{P}^{5+}$ by counter-valent ions. ${ }^{6,8}$ During room-temperature $\mathrm{HCHO}$ combustion on HAp, the hydroxyl groups bonded with the channel $\mathrm{Ca}^{2+}\left(\mathrm{HO} \cdots \mathrm{Ca}^{2+}\right.$, blue oxyanion in Figure 1c) may act as the active sites, as illustrated in Figure 4. The main steps for this reaction can be concisely described as follows: (i) molecular oxygen first adsorbing on HAp with one $\mathrm{O}$ atom bonding to $\mathrm{Ca}^{2+}$ and the other $\mathrm{O}$ on the $\mathrm{C}$ in $\mathrm{HCHO}$; (ii) the two $\mathrm{H}$ atoms of $\mathrm{HCHO}$ interacting with the two

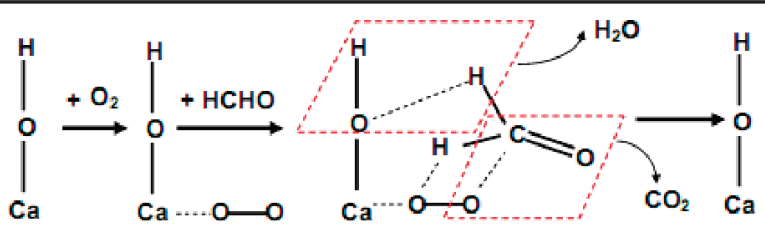

Figure 4. Scheme of HCHO combustion on HAp while hydroxyl groups connected to $\mathrm{Ca}^{2+}$ serve as active sites.

O's that are bound to $\mathrm{Ca}^{2+}$ (one from $\mathrm{OH}$ and the other from adsorbed dioxygen); and (iii) $\mathrm{CO}_{2}$ and $\mathrm{H}_{2} \mathrm{O}$ produced by simultaneous breaking of $\mathrm{Ca}-\mathrm{O}, \mathrm{O}-\mathrm{O}$, and $\mathrm{C}-\mathrm{H}$ bonds. While only a small amount of oxygen is perhaps weakly adsorbed through bonding to $\mathrm{Ca}^{2+}$, this may be enhanced in the presence of $\mathrm{HCHO}$ due to the formation of $\mathrm{O}-\mathrm{H}$ bonds, and this may explain why there is almost no $\mathrm{HCHO}$ oxidation on HAp during the TPSR experiment in the absence of adsorbed oxygen (Figure 3).

In summary, we report for the first time the excellent performance of HAp foam for HCHO combustion under ambient conditions. Preliminary results reveal that hydroxyl groups bonded to $\mathrm{Ca}^{2+}$ inside channels of HAp may play an important role in adsorption/ activation of $\mathrm{HCHO}$, and a plausible catalytic cycle is proposed to explain the reaction mechanism. Owing to the complexity of this system, more evidence, especially the characterization of $\mathrm{HCHO}$ and its intermediates on the HAp surface during reaction, is required. It is suggested that further improvements in activity may be possible by modifying the local environment of the channel Ca---OH groups through partial replacement of $\mathrm{Ca}^{2+}$ with other metals such ferric iron $\left(\mathrm{Ca}^{2+}+\mathrm{OH}^{-} \leftrightarrow \mathrm{Fe}^{3+}+\mathrm{O}^{2-}\right)$ or rare earth elements $\left(\mathrm{Ca}^{2+}+\right.$ $\left.2 \mathrm{P}^{5+} \leftrightarrow \mathrm{Ce}^{4+}+2 \mathrm{Si}^{4+} ; \mathrm{Ca}^{2+}+\mathrm{P}^{5+} \leftrightarrow \mathrm{Ce}^{3+}+\mathrm{Si}^{4+}\right)$ to improve oxygen absorption, and such studies are ongoing. This work gives strong support to the notion that non-precious metal oxide porous ceramics may be designed from inexpensive materials with active sites for promoting low-temperature catalytic combustion of VOCs and other organic pollutants.

Acknowledgment. The authors are grateful to the support from the Chinese Education Ministry 111 project (B08021), NonGovernment International Cooperation Project of Shanghai Ministry of Science and Technology (2010/10230705 900), Shanghai PuJiang Talent Program (2010/10PJ1402500), and Fundamental Research Funds for the Central Universities.

Supporting Information Available: HAp structure, characterization, calculations, and experimental section. This material is available free of charge via the Internet at http://pubs.acs.org.

\section{References}

(1) Zhang, C.; He, H. Catal. Today 2007, 126, 345-350.

(2) Li, C.; Shen, Y.; Jia, M.; Sheng, S.; Adebajo, M. O.; Zhu, H. Catal. Commun. 2008, 9, 355-361.

(3) Álvarez-Galván, M. C.; Pawelec, B.; de la Peña O’Shea, V. A.; Fierro, J. L. G.; Arias, P. L. Appl. Catal. B: Environ. 2004, 51, 83-91.

(4) Imamura, S.; Uematsu, Y.; Utani, K.; Ito, T. Ind. Eng. Chem. Res. 1991, 30, 1821.

(5) Kielin, E. J.; Brown, K. G. D’Ambrosia, C. M. U.S. patent 5585083, 1996

(6) White, T.; Ferraris, C.; Kim, J.; Madhavi, S. Rev. Mineral. Geochem. 2005, 57, 307-401.

(7) Mori, K.; Hara, T.; Mizugaki, T.; Ebitani, K.; Kaneda, K. J. Am. Chem. Soc. 2003, 125, 11460-11461.

(8) Opre, Z.; Ferri, D.; Krumeich, F.; Mallat, T.; Baiker, A. J. Catal. 2007, 251, 48-58.

(9) Tsuchida, T.; Kubo, J.; Yoshioka, T.; Sakuma, S.; Takeguchi, T.; Ueda, W. J. Catal. 2008, 259, 183-189.

(10) Kamitakahara, M.; Takahashi, A.; Tanihara, M.; Kawachi, G.; Ohtsuki, C. J. Ceram. Soc. Jpn. 2007, 115, 425-428.

(11) Han, Y.-F.; Phonthammachai, N.; Ramesh, K.; Zhong, Z.; White, T. Environ. Sci. Technol. 2008, 42, 908-912.

JA1058923 